Research Article

\title{
Numerical Study on Shear Performance of a New Perfobond Connector with Controllable Stiffness
}

\author{
Yangqing Liu, ${ }^{1}$ Yuqing Liu $\mathbb{D}^{1},{ }^{1}$ Haohui Xin $\mathbb{D},{ }^{1,2}$ Hao Tian, ${ }^{3,4}$ and Jun Wei $\mathbb{C}^{3,4}$ \\ ${ }^{1}$ Department of Bridge Engineering, Tongji University, Shanghai, China \\ ${ }^{2}$ Faculty of Civil Engineering and Geosciences, Delft University of Technology, Delft, Netherlands \\ ${ }^{3}$ Zhejiang Scientific Research Institute of Transport, Hangzhou, China \\ ${ }^{4}$ Key Laboratory of Road and Bridge Inspection and Maintenance Technology of Zhejiang Province, Hangzhou, China \\ Correspondence should be addressed to Jun Wei; weijun@zjjtkyy.com
}

Received 18 March 2020; Accepted 8 June 2020; Published 3 August 2020

Academic Editor: Veronica Calado

Copyright $\odot 2020$ Yangqing Liu et al. This is an open access article distributed under the Creative Commons Attribution License, which permits unrestricted use, distribution, and reproduction in any medium, provided the original work is properly cited.

\begin{abstract}
To improve the shear behavior and design applicability of rubber ring perfobond connectors (RPBLs), a new rubber ring that aims to make the shear stiffness of RPBLs controllable was proposed. Firstly, the conceptual design and configuration of the new rubber rings were presented and discussed. Subsequently, finite element (FE) models for modified push-out tests of new RPBLs were established based on the validated modeling method. The initial shear stiffness is dominated by the horizontal projected contact area between hole walls and concrete dowels. $\gamma$ is defined as the ratio of the horizontal projected length of hollows to the diameter of holes. The shear stiffness of new RPBLs is about $35 \%, 60 \%$, and $82 \%$ of the shear stiffness of PBLs when $\gamma$ equals $0.25,0.5$, and 0.75 , respectively. Employing the new rubber rings with varying central angles on conventional PBLs is feasible to obtain the required stiffness for RPBLs. Further, the effects of the number of sectors, the size of side wings, the central angle of hollows, the offset angle, and the thickness of rubber rings were analysed. Based on the numerical results, the proper thickness of side wings is no larger than $2 \mathrm{~mm}$. The thicker side wing could reduce the confinement effects provided by surrounding concrete on concrete dowels, resulting in a drop of the yield load of new RPBLs. The number of sectors is suggested to be no less than 6 so that the shear behavior of new RPBLs is irrelevant to the offset angle. Besides, the shear stiffness is not related to the thickness of rubber rings. To improve the yield load of RPBLs and obtain the moderate recovered stiffness, the thickness of rubber rings is recommended as $2 \mathrm{~mm}$. Finally, the expression for the shear stiffness of new RPBLs was proposed.
\end{abstract}

\section{Introduction}

Perfobond connectors (PBL) are increasingly used in steelconcrete composite structures due to their excellent shear and fatigue capacity $[1,2]$. As shown in Figure 1, PBLs are usually employed as a group with multiple rows and columns in practical applications, such as the joints of hybrid girders, the interfaces of composite girders with corrugated webs, the interfaces of hybrid trusses, and the anchorage joints between suspenders and girders [3]. However, the shear distribution in PBL groups is significantly uneven [3], resulting in that parts of PBLs have been in the plastic state. Although the average shear force of each PBL is below the design strength, the design of the steel-concrete connection could be unsafe especially under fatigue loading.

Although many researchers investigated the shear behavior of PBLs $[4,5]$, the studies on the shear performance of PBL groups are limited. Oguejiofor [6] reported that the interactions between adjacent holes could limit the increase of shear capacity when the ratio of the hole spacing to the hole diameter was less than 2.25. Su [7] concluded that the shear capacity of each hole in the group with two holes could not be fully developed, and a reduction factor of 0.9 should be introduced. Besides, Liu [3] found that the shear percentage of holes was affected by the stiffness ratio of PBLs to steel plates and the number of holes. 


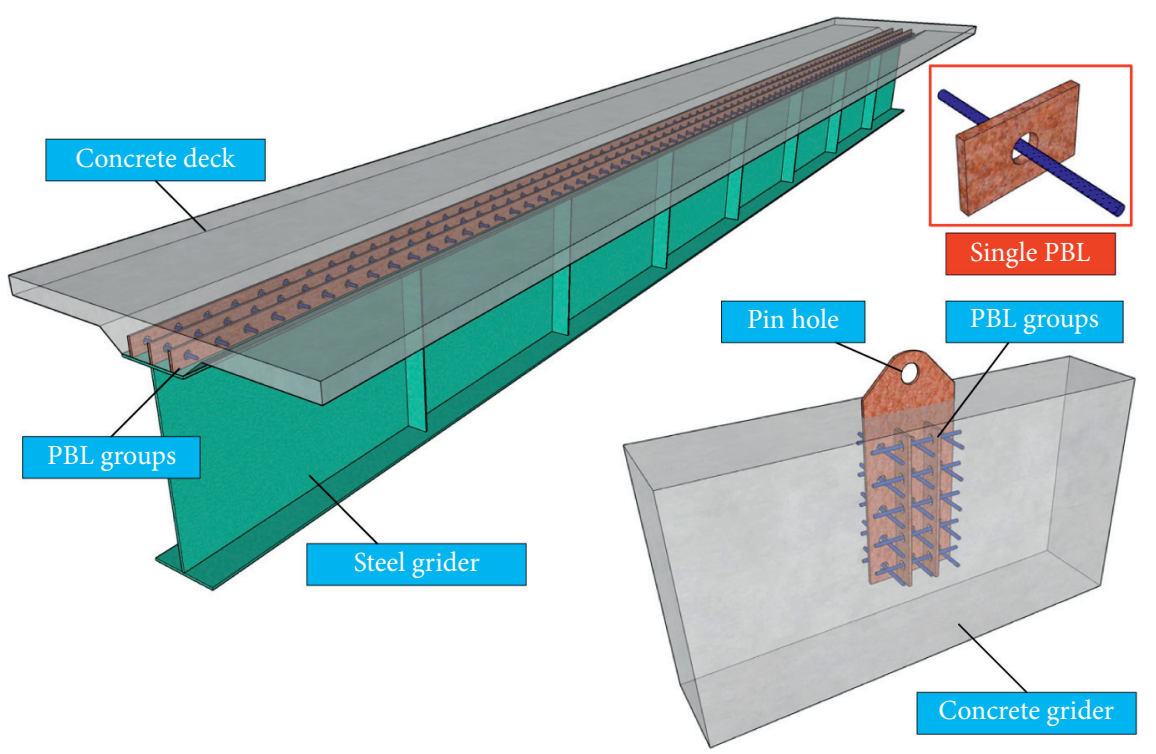

FIgURE 1: Applications of PBL groups.

Since the shear distribution of PBL groups is relevant to the shear stiffness of PBLs, a feasible solution for alleviating the shear concentration is to reduce the shear stiffness of partial connectors. Rubber is a kind of hyperelastic material that is much softer than steel and concrete. It is convenient to control the contact area between steel and concrete by using rubber. Based on this concept, $\mathrm{Xu}[8,9]$ put forward a headed stud with rubber sleeves, which could provide lower shear stiffness for headed stud connectors. Subsequently, Liu [10] proposed a rubber ring that can be easily installed on conventional PBLs and conducted modified push-out tests and refined $\mathrm{FE}$ analyses to evaluate the shear behavior of the rubber ring perfobond connector (RPBL). The results showed that RPBLs presented very low initial shear stiffness, and the slip starting resisting shear forces could be controlled through the thickness of rubber rings. By employing rubber rings on partial PBLs in groups, the shear distribution tends to be uniform. However, the shear stiffness of the current RPBL is not controllable, which is hard to consider in designs quantitatively. As far as the authors' knowledge, the studies on alleviating shear concentration in PBL groups are still limited.

In this paper, a new rubber ring that aims to make the shear stiffness of RPBLs controllable was proposed. The conceptual design and configuration of the new rubber rings were presented and discussed. Subsequently, FE models for modified push-out tests of new RPBLs were established based on the validated modeling method [10]. Further, a proposal selection among 3 types of rubber rings was conducted according to the numerical results. The applicability of the new RPBLs was demonstrated. The effects of the number of sectors, the size of side wings, the central angle of hollows, the offset angle, and the thickness of rubber rings were analysed. Finally, the reasonable geometric parameters of new rubber rings were provided. The expression for the shear stiffness of new RPBLs was proposed.

\section{New Rubber Rings}

2.1. Conceptual Design. According to the analyses performed in [10], the rubber rings can effectively decrease the initial stiffness of PBLs and improve the slip capacity of PBLs. However, the RPBLs with current rubber rings present negligible initial shear stiffness, which is uncontrollable. The reason is that there is no contact area between hole walls and concrete dowels. To improve the initial stiffness of RPBLs and make it controllable, 3 types of new rubber rings are put forward in this study, as shown in Figure 2. Based on the previous responses, the side wings could effectively prevent the rubber rings from dropping from the holes. Hollows with different central angles and positions are employed along the circumference to enlarge the contact area between steel and concrete.

In terms of Type-A, two hollows with large central angles are set on the left and right sides of the circumference. At the early loading stage, the hole contacts the concrete dowel on the sides. The contact area between steel and concrete along the loading direction decreases by using Type-A rubber rings. In contrast, the contact area along the tensile direction, which is perpendicular to the loading direction, is the same as that of PBLs. In terms of Type-B, the hole contacts with the middle parts of the concrete dowel so that the initial stiffness of connectors is expected to be smaller than that of PBLs and larger than that of current RPBLs. Besides, the RPBLs with Type-B rubber rings could present very low stiffness on the direction perpendicular to the loading direction, which might be useful in some applications.

However, Type-A and Type-B present the anisotropy performance which is inconvenient and hard to install on site precisely. To improve the practicability of RPBLs, the isotropic Type- $\mathrm{C}$ rubber ring is proposed. The isotropy is formed by the proper array of hollows and rubber. There are more than 4 sectors with the same angle evenly distributing along the circumference. The stiffness of RPBLs by using 


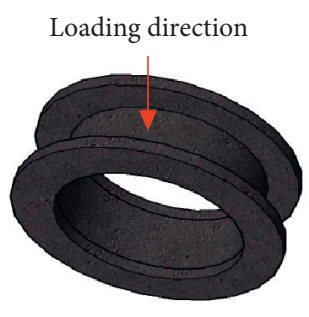

Current rubber ring

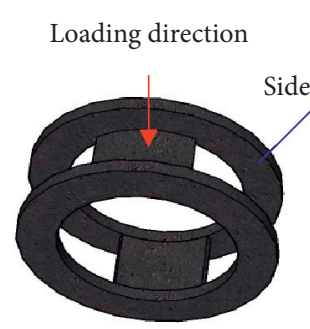

New rubber ring type-A
Loading direction

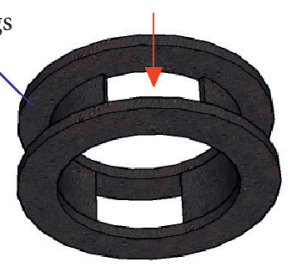

New rubber ring type-B

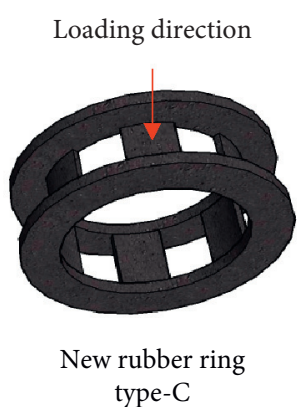

type-C

Figure 2: New rubber rings.

Type- $\mathrm{C}$ rubber rings could be very close in different directions so that contractors do not need to care about the rotation of rubber rings during installations.

2.2. Details. Figure 3 shows the geometry details of 3 new rubber rings, where $\theta$ is the central angle of a hollow in a periodical sector; $n_{s}$ is the total number of sectors along the circumference; $o$ is the offset angle of rubber rings, which equals 0 when the middle of a hollow is at the central line of the hole. $t_{r}$ and $t_{w}$ are the thickness of rubber rings and side wings, respectively. $l_{w}$ is the length of side wings. The previous test results [10] showed that the current rubber rings reduced the yield load of PBLs. The reason is that the improper wing size weakens the concrete confinement effects provided by surrounding concrete on concrete dowels. Therefore, the reasonable dimensions of the new rubber rings, as well as the side wings, were investigated by FE models in Section 4.

\section{Finite Element Models}

To evaluate the shear behavior of perfobond connectors with the new rubber rings, numerical simulation was conducted in this study. Referring to the validated modeling method [10], solid finite element models for the modified push-out tests of RPBLs using the new rubber rings were built by ABAQUS/Explicit [11]. Figure 4 shows the components of the FE models, including the perfobond plates, new rubber rings, perforated rebars, concrete blocks, distributed reinforcements, and the rigid ground. Among the parts of the models, all of them were simulated by the $3 \mathrm{D}$ 8-node reduced integration element C3D8R except for the distributed reinforcements and the rigid ground, which were built by the linear truss element T3D2 and the rigid element R3D4, respectively.

The boundary condition of the models was consistent with that of the corresponding modified push-out tests. All the degrees of freedom of the reference point on the rigid ground were restrained. The bottom surface of concrete blocks contacted the top surface of the rigid ground. As regards the loading, the uniform displacement load was applied to the loading surface, as shown in Figure 4. Tie constraints were employed at the interfaces between perforated rebars and concrete blocks. In contrast, contact pairs were built between the surfaces of perfobond plates and concrete clocks, hole walls and concrete dowels, new rubber rings and perfobond plates as well as concrete components. The normal behavior of the contact pairs about pressureoverclosure was set as "hard." For the simplification of the discussion, frictions and cohesive properties were ignored in this study.

As regards the material properties, concrete was simulated by Concrete Damage Plasticity Model (CDPM) provided by ABAQUS [11]. The compressive stress-strain curve and the tensile stress-crack width relationship were introduced by CEB-FIP MC2010 and reference [12, 13]. The trilinear stress-strain relationship was used for perfobond plates and rebars [13]. The hyperelastic rubber was described by strain potential energy [11]. More details about material properties can be referred to the authors' previous publication [10].

\section{Parametric Study}

4.1. Proposal Selection. In this section, a parametric study with $28 \mathrm{FE}$ models was conducted to evaluate the feasibility and design recommendation of new rubber rings. Comparisons of the geometric shapes and the shear-slip curves were presented among the models with varying parameters, including the types, wing sizes, central angles, offset angles, and rubber ring thickness. Table 1 summarizes the results of the numerical parametric study, where $d$ is the hole diameter which equals $60 \mathrm{~mm}$ in this study; $l_{p}$ is the sum of the horizontal projected length of hollows; $\gamma$ is the ratio of $l_{p}$ to $d . k_{s}$ and $V_{y}$ are the shear stiffness and yield loads of models, respectively [10].

Firstly, the feasibility of the conceptual designs of TypeA, Type-B, and Type-C rubber rings was discussed. Figure 5 shows the geometry of Type-A rubber rings with varying central angles that are of $151^{\circ}, 120^{\circ}$, and $83^{\circ}$. Two hollows are set on the left and right sides of the circumference. The corresponding horizontal projected lengths of the hollows are $0.75 d, 0.5 d$, and $0.25 d$, respectively. The projected length of hollows directly affects the contact area between hole walls and concrete dowels, which is the dominant factor in the initial shear stiffness of PBLs. Besides, the thickness and length of the side wings are $4 \mathrm{~mm}$ and $10 \mathrm{~mm}$, respectively, which are the same as the current rubber rings [10]. The thickness of the rubber rings is $2 \mathrm{~mm}$.

Figures 6(a) and 6(b) show the shear force-slip curves of the FE models, where the label A_ $\theta 151$ denotes the Type-A rubber ring whose central angle is $151^{\circ}$. The shear force-slip 


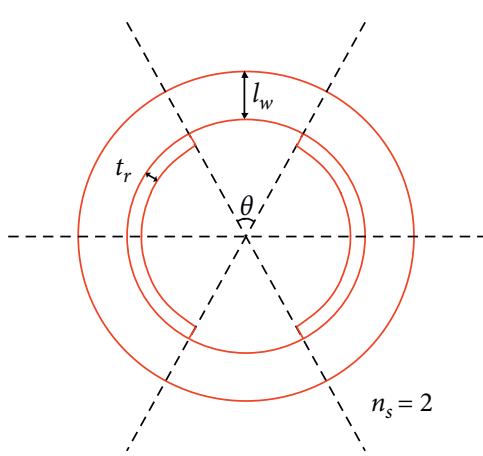

(a)

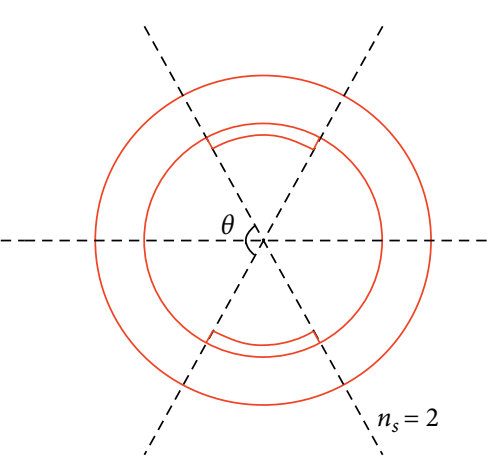

(b)

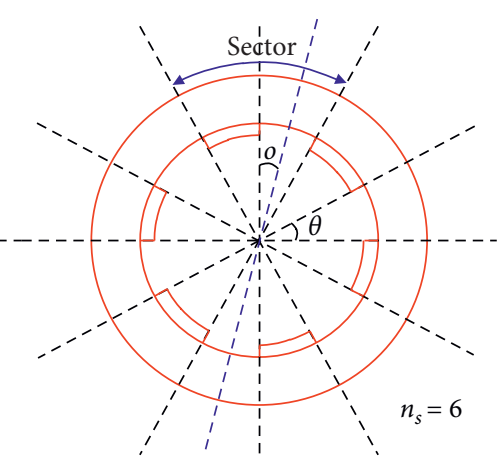

(c)

Figure 3: Configuration of new rubber rings. (a) Type-A. (b) Type-B. (c) Type-C.

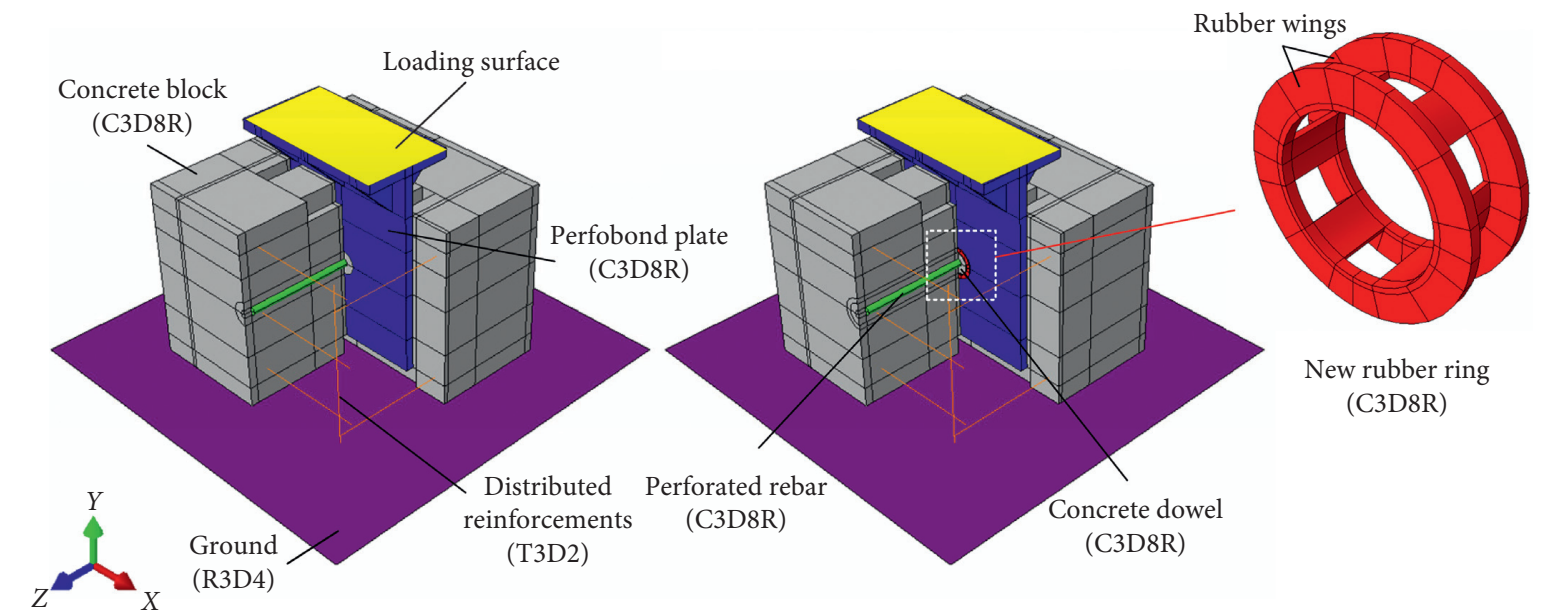

Figure 4: Finite element models.

curves of new RPBLs consist of 3 stages. Firstly, the models present moderate stiffness at the initial loading stage due to the existence of hollows. Subsequently, since the rubber rings deform to some extent, the shear forces rise and fall as the slip develops. The shear stiffness of the new RPBLs is very low in the second stage. Further, with the increase of slips, the stiffness recovers, and the shear force increases to the yield load of RPBLs. The recovered stiffness is relatively larger in the case that the smaller central angle of hollows is provided.

From Figure 6(b), the initial shear stiffness of the new RPBLs is smaller than that of the conventional perfobond connector (PBL) and increases with the central angle. Figure 5(c) indicates that the shear stiffness is briefly linear with $\gamma$. The shear stiffness is $35 \%, 60 \%$, and $82 \%$ of the shear stiffness of PBLs when $\gamma$ equals $0.25,0.5$, and 0.75 , respectively. The results demonstrate that Type-A rubber rings are feasible to make the stiffness of PBLs controllable. However, the yield loads of the new RPBLs are similar to the current RPBLs, which is noticeably smaller than that of PBLs. The reason might be related to the size of side wings, whose impacts are illustrated in the next section. The effect of $\gamma$ on the yield load of the new RPBL is negligible.

Compared with Type-A, the middle of the two hollows is positioned on the central line of rubber rings in Type-B.
Figure 7 shows the geometry of Type-B rubber rings with varying central angles that are of $97^{\circ}, 60^{\circ}$, and $29^{\circ}$. Consistent with Type-A, the corresponding horizontal projected lengths of the hollows are $0.75 \mathrm{~d}, 0.5 \mathrm{~d}$, and $0.25 \mathrm{~d}$, respectively. The size of rubber rings and wings is also the same as that of Type-A. Figure 8 shows the shear force-slip curves of the FE models employing Type- $\mathrm{B}$ rubber ring with the varying central angles. The shear performance of the Type-B RPBLs is similar to that of the Type-A RPBLs. They all present a moderate stiffness at the initial loading stage, which increases with the central angles of hollows. After the platform of shear forces at the second stage, the stiffness recovers as the slip grows. Compared with the Type-A rubber rings, the difference in the recovered stiffness at the third stage is smaller.

Figures $8(\mathrm{~b})$ and $8(\mathrm{c})$ present the initial shear stiffness of the Type-B RPBLs, which are in a similar trend with the results of the Type-A RPBLs. The shear stiffness is $42 \%, 65 \%$, and $87 \%$ of the shear stiffness of PBLs when $\gamma$ equals 0.25 , 0.5 , and 0.75 , respectively. By using the same horizontal projected lengths of the hollows, the shear stiffness of Type-B is slightly higher than that of Type-A. This illustrates that the initial shear stiffness of PBLs and RPBLs is dominated by the projected contact area between hole walls and concrete dowels, but the contribution of the region near the center of 
TABLE 1: Summary of parametric study results.

\begin{tabular}{|c|c|c|c|c|c|c|c|c|c|c|c|}
\hline Model & $t_{r}(\mathrm{~mm})$ & $t_{w}(\mathrm{~mm})$ & $l_{w}(\mathrm{~mm})$ & Type & $n_{s}$ & $\theta\left({ }^{\circ}\right)$ & $o\left(^{\circ}\right)$ & $k_{s}(\mathrm{kN} / \mathrm{mm})$ & $l_{p}(\mathrm{~mm})$ & $\gamma$ & $V_{y}(\mathrm{kN})$ \\
\hline PBL & - & - & - & - & - & - & - & 547.3 & 60.0 & 1.00 & 443.9 \\
\hline RPBL & 2 & 2 & 10 & Cur. & - & - & - & 7.5 & 0.0 & 0.00 & 376.4 \\
\hline A_ $\theta 151$ & 2 & 4 & 10 & A & 2 & 151 & 90 & 446.6 & 45.0 & 0.75 & 327.5 \\
\hline A_ $\theta 120$ & 2 & 4 & 10 & A & 2 & 120 & 90 & 330.4 & 30.0 & 0.50 & 325.9 \\
\hline A_$\theta 83$ & 2 & 4 & 10 & A & 2 & 83 & 90 & 193.0 & 15.0 & 0.25 & 323.6 \\
\hline B_ $\theta 97$ & 2 & 4 & 10 & B & 2 & 97 & 0 & 477.9 & 45.0 & 0.75 & 324.4 \\
\hline B_ $\theta 60$ & 2 & 4 & 10 & B & 2 & 60 & 0 & 356.9 & 30.0 & 0.50 & 314.5 \\
\hline B_ $\theta 29$ & 2 & 4 & 10 & B & 2 & 29 & 0 & 229.9 & 15.0 & 0.25 & 308.3 \\
\hline C_ns4_ $\theta 45 \_o 0$ & 2 & 4 & 10 & $\mathrm{C}$ & 4 & 45 & 0 & 361.3 & 27.5 & 0.46 & 338.5 \\
\hline C_ns4_ $\theta 45 \_023$ & 2 & 4 & 10 & $\mathrm{C}$ & 4 & 45 & 22.5 & 268.9 & 30.0 & 0.50 & 340.8 \\
\hline C_ns6_O30_o0 & 2 & 4 & 10 & $\mathrm{C}$ & 6 & 30 & 0 & 316.3 & 31.1 & 0.52 & 339.3 \\
\hline C_ns6_t30_o15 & 2 & 4 & 10 & $\mathrm{C}$ & 6 & 30 & 15 & 372.5 & 30.0 & 0.50 & 346.0 \\
\hline C_tw4_lw10 & 2 & 4 & 10 & $\mathrm{C}$ & 6 & 30 & 0 & 316.3 & 31.1 & 0.52 & 339.3 \\
\hline C_tw4_lw6 & 2 & 4 & 6 & $\mathrm{C}$ & 6 & 30 & 0 & 328.1 & 31.1 & 0.52 & 365.6 \\
\hline C_tw2_lw10 & 2 & 2 & 10 & $\mathrm{C}$ & 6 & 30 & 0 & 351.1 & 31.1 & 0.52 & 437.6 \\
\hline C_tw2_lw6 & 2 & 2 & 6 & $\mathrm{C}$ & 6 & 30 & 0 & 309.2 & 31.1 & 0.52 & 438.9 \\
\hline C_ns6_- $\theta 45$ & 2 & 2 & 10 & $\mathrm{C}$ & 6 & 45 & 0 & 528.4 & 45.9 & 0.77 & 428.5 \\
\hline C_ns6_ $\theta 30$ & 2 & 2 & 10 & $\mathrm{C}$ & 6 & 30 & 0 & 351.1 & 31.1 & 0.52 & 437.6 \\
\hline C_ns6_- $\theta 15$ & 2 & 2 & 10 & $\mathrm{C}$ & 6 & 15 & 0 & 120.1 & 15.7 & 0.26 & 439.1 \\
\hline C_ns6_o0 & 2 & 2 & 10 & $\mathrm{C}$ & 6 & 30 & 0 & 351.1 & 31.1 & 0.52 & 437.6 \\
\hline C_ns6_o8 & 2 & 2 & 10 & $\mathrm{C}$ & 6 & 30 & 7.5 & 344.3 & 30.8 & 0.51 & 439.6 \\
\hline C_ns6_o15 & 2 & 2 & 10 & $\mathrm{C}$ & 6 & 30 & 15 & 408.4 & 30.0 & 0.50 & 434.5 \\
\hline C_ns6_o23 & 2 & 2 & 10 & $\mathrm{C}$ & 6 & 30 & 22.5 & 355.7 & 29.2 & 0.49 & 438.0 \\
\hline C_ns6_o30 & 2 & 2 & 10 & $\mathrm{C}$ & 6 & 30 & 30 & 289.8 & 28.9 & 0.48 & 443.7 \\
\hline C_ns6_tr 1.5 & 1.5 & 2 & 10 & $\mathrm{C}$ & 6 & 30 & 0 & 345.8 & 31.1 & 0.52 & 430.0 \\
\hline C_ns6_tr2 & 2 & 2 & 10 & $\mathrm{C}$ & 6 & 30 & 0 & 351.1 & 31.1 & 0.52 & 437.6 \\
\hline C_ns6_tr3 & 3 & 2 & 10 & $\mathrm{C}$ & 6 & 30 & 0 & 354.7 & 31.1 & 0.52 & 360.2 \\
\hline C_ns6_tr4 & 4 & 2 & 10 & $\mathrm{C}$ & 6 & 30 & 0 & 299.1 & 31.1 & 0.52 & 348.9 \\
\hline
\end{tabular}

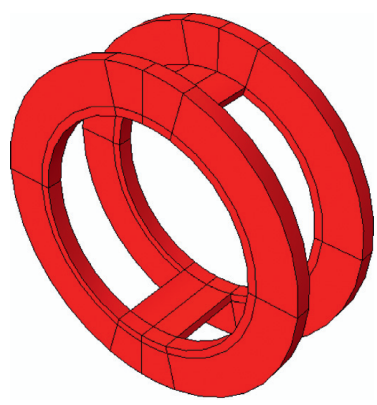

(a)

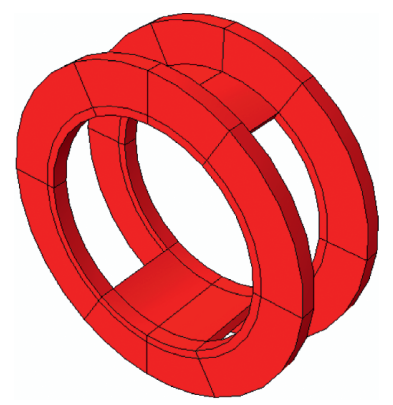

(b)

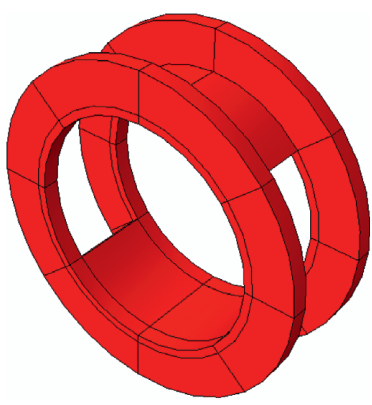

(c)

Figure 5: Type-A rubber rings with varying central angles: (a) $\theta=151^{\circ}$, (b) $\theta=120^{\circ}$, (c) $\theta=83^{\circ}$.

holes is larger than that of the region on the side of holes. The projected contact area is not only affected by the central angle but also influenced by the offset angle. In other words, the shear stiffness of RPBLs might be controllable by changing the shape parameters of rubber rings, including the central angles of hollows and the offset angles of rubber rings.

Although Type-A and Type-B rubber rings could make the shear stiffness controllable, their anisotropy sometimes is unfavorable, especially on the condition of the requirement of precise installations. An alternative solution is the isotropic Type-C rubber ring, whose isotropy is formed by the uniform array of hollows and rubber. Figure 9 shows the Type-C rubber rings with varying numbers of periodical sectors and offset angles. The central angles are $45^{\circ}$ and $30^{\circ}$ for the cases that $n_{s}=4$ and $n_{s}=6$, respectively. For each number of sectors, the situations that the offset angles equal 0 and half of the central angle are investigated. The proper number of sectors that can reduce the impact of offset angles on the shear behavior of RPBLs is explored.

Figure 10 shows the shear force-slip curves of the FE models employing Type- $C$ rubber rings. The curves consist of 3 stages that are the same as those of Type-A and Type- $B$ rubber rings. The effects of offset angles on the global shear performance of Type-C RPBLs are slight. However, Figure 10(b) reflects that the difference in the shear stiffness of the Type-C RPBLs with varying offset angles is considerable when $n_{s}=4$. The reason is that the range of the offset angle is relatively broad on the condition that $n_{s}$ is small, 


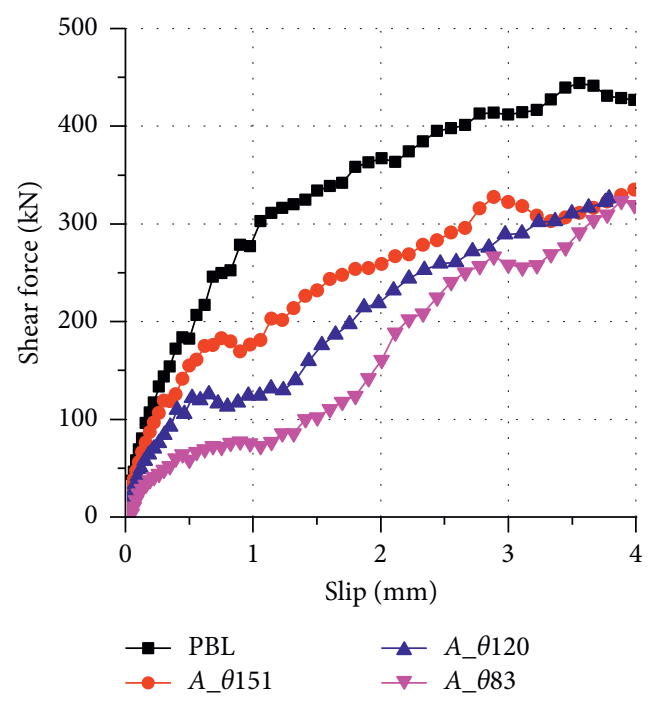

(a)

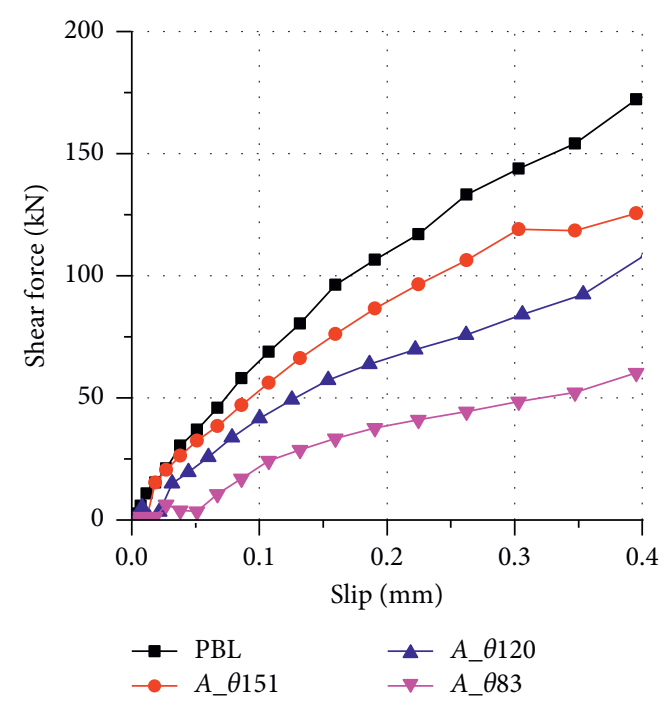

(b)

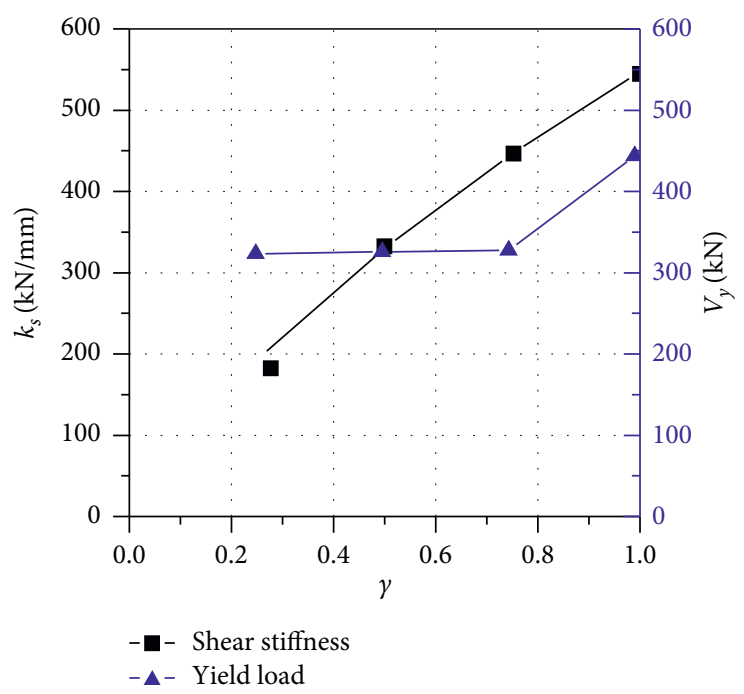

(c)

Figure 6: Shear behavior of Type-A rubber rings. (a) Global shear behavior. (b) Initial shear stiffness. (c) Effects of $\gamma$.

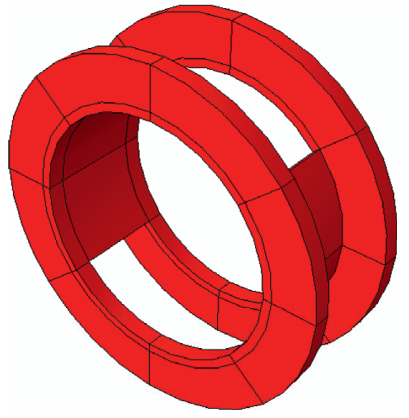

(a)

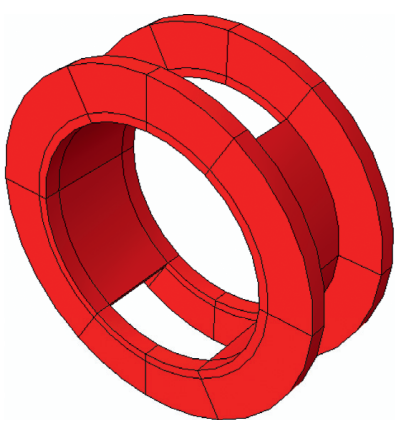

(b)

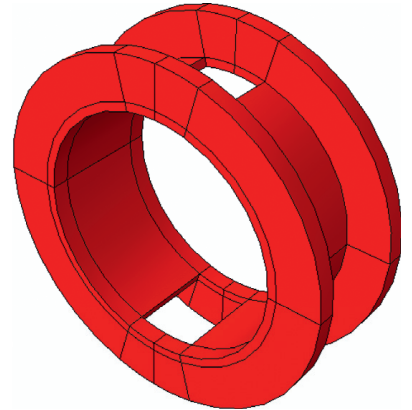

(c)

FIgURE 7: Type-B rubber rings with varying central angles: (a) $\theta=97^{\circ}$, (b) $\theta=60^{\circ}$, (c) $\theta=29^{\circ}$.

resulting in the significant variation of the horizontal projected area. Compared with Figure 10(b), Figure 10(d) illustrates that the impact of offset angles on the shear stiffness is smaller when $n_{s}=6$. Therefore, the number of periodical sectors of Type- $\mathrm{C}$ rubber rings is recommended to be no less than 6. 


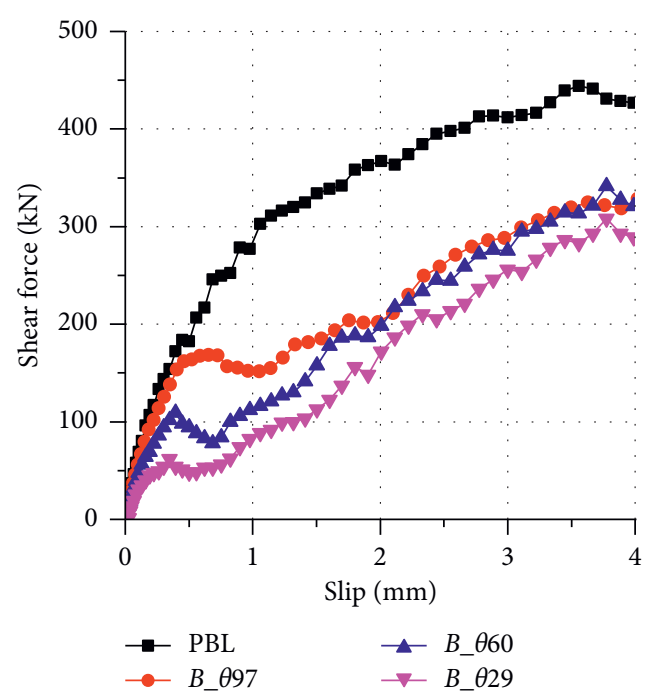

(a)

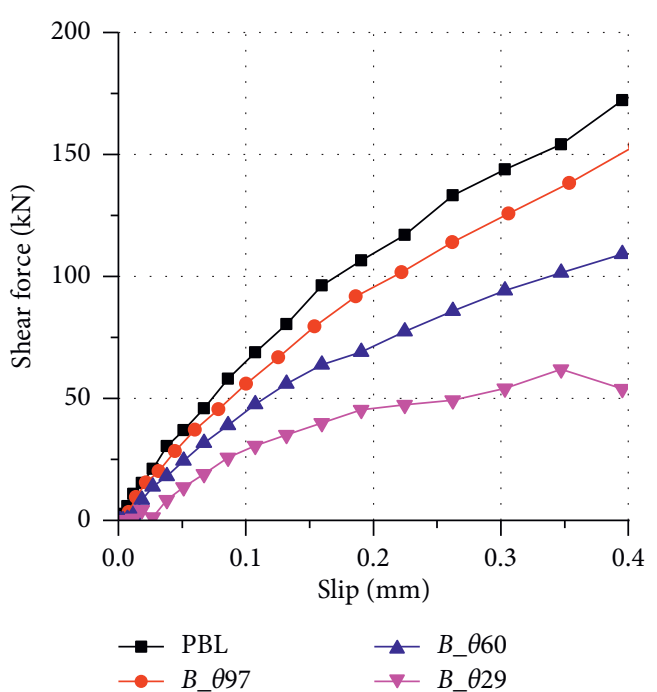

(b)

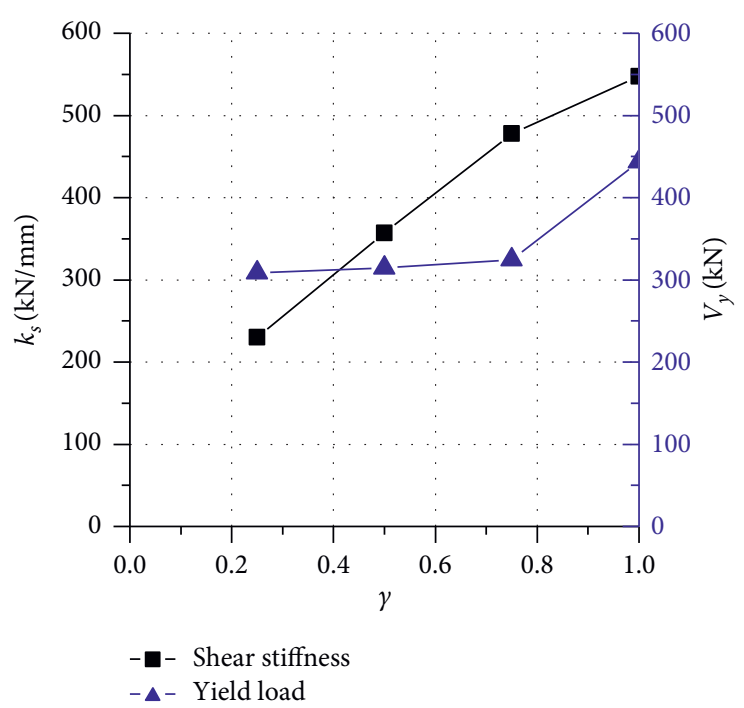

(c)

FIgURE 8: Shear behavior of Type-B rubber rings. (a) Global shear behavior. (b) Initial shear stiffness. (c) Effects of $\gamma$.

Based on the analyses above, the new rubber rings are feasible to decrease the initial shear stiffness of PBLs and even make them controllable. Among the 3 types of new rubber rings, Type- $\mathrm{C}$ is isotropic and not sensitive to the installation errors, such as the rotational offset, when the number of periodical sectors is no less than 6. Consequently, the Type- $C$ rubber ring is selected as the proposed new rubber ring in this study. The proper side wing sizes, the effects of central angles and offset angles, and the impacts of rubber ring thickness are investigated in the following sections.

4.2. Effects of Wing Size. Figure 11 shows the new rubber rings with varying thicknesses and lengths of side wings. The number of sectors, central angles of hollows, and offset angles are $6^{\circ}, 30^{\circ}$, and $0^{\circ}$, respectively. The previous test results [10] showed that the yield load of the current RPBL is lower than that of the corresponding conventional PBLs. The side wing of the current rubber ring employs a thickness of $4 \mathrm{~mm}$ and a length of $10 \mathrm{~mm}$, which are the same as the new rubber ring shown in Figure 11(a). To improve the shear bearing capacity and provide sufficient simplicity of installation, the combination of the smaller wing thickness of $2 \mathrm{~mm}$ and length of $6 \mathrm{~mm}$ is considered in this investigation.

Figures 12(a) and 12(b) show the shear force-slip curves of the new RPBLs with the different wing sizes. From Figure 12(a), the shear behavior of the models at the early loading stage is close. However, the recovered stiffness at the third stage and the yield load of RPBLs increase as the thickness of side wings decreases. Figures 12(b) and 12(c) illustrate that the initial shear stiffness of the new RPBLs is irrelevant to the size of side wings.

Figure 12(d) shows the effects of wing sizes on the yield load of new RPBLs. The yield loads of the models with a wing thickness of $2 \mathrm{~mm}$ are higher than those of the $4 \mathrm{~mm}$-thick 


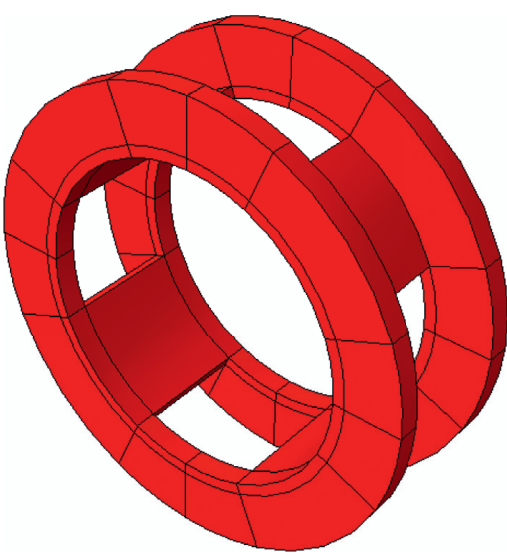

(a)

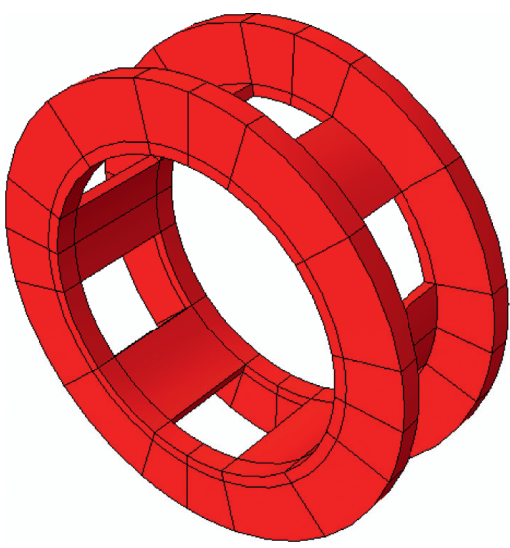

(c)

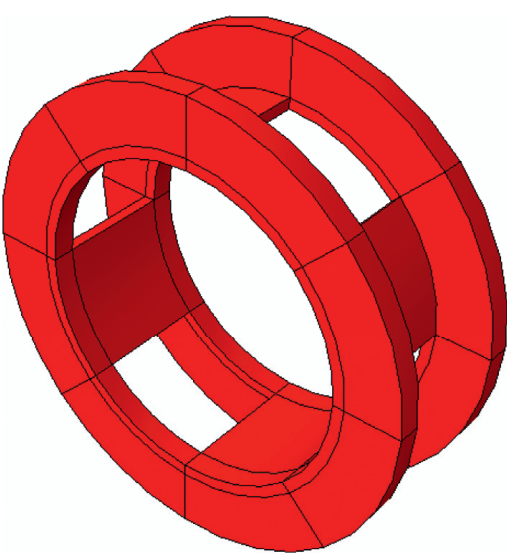

(b)

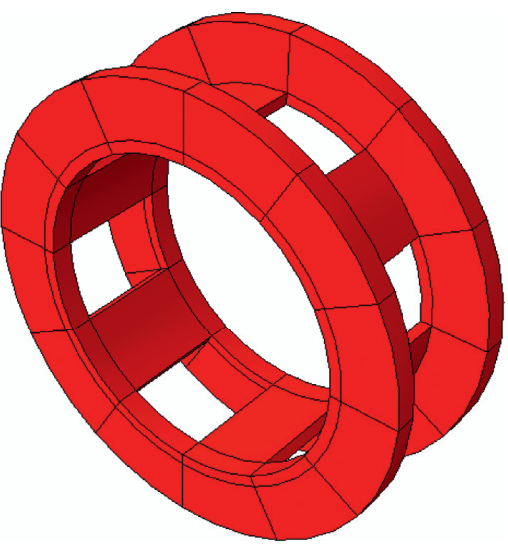

(d)

FIGURE 9: Type-C with varying numbers of sectors and offset angles: (a) $n_{s}=4, o=0^{\circ}$, (b) $n_{s}=4, o=22.5^{\circ}$, (c) $n_{s}=6, o=0^{\circ}$, (d) $n_{s}=6, o=15^{\circ}$.

models and are close to that of the conventional PBL. The reason is that the thicker side wing diminishes the confinement effect provided by surrounding concrete on the concrete dowel. Thus, the recommended wing thickness is no larger than $2 \mathrm{~mm}$. In contrast, the impact of the length of side wings on the shear performance is negligible. On the consideration of the installation of rubber rings, the length of side wings is suggested to be $10 \mathrm{~mm}$. To sum up, the dimension of wings is determined as $2 \mathrm{~mm} \times 10 \mathrm{~mm}$ in the following analyses.

4.3. Effects of Central Angle. Figure 13 shows the new rubber rings with the hollow central angles of $15^{\circ}, 30^{\circ}$, and $45^{\circ}$, where the number of sectors and the offset angle are $6^{\circ}$ and $0^{\circ}$, respectively. Since the number of sectors is 6 , the central angle of one periodical sector is $60^{\circ}$. The central angle ratio of hollows to rubber affects the horizontal projected area of the hollows, which is a dominant factor in the initial shear stiffness of RPBLs. Besides, the offset angle equals 0 in these 3 models.

Figure 14 compares the shear force-slip curves of the new RPBLs with different central angles. It is noted that the central angle of hollows significantly affects the early-stage shear behavior of RPBLs. The shear stiffness is $22 \%$ of the shear stiffness of $\mathrm{PBL}$ when the central angle equals $15^{\circ}$, and the corresponding $\gamma$ is 0.26 , while the shear stiffness ratio of C_ns6_ $\theta 45$ to PBL is $96 \%$ when the central angle equals $45^{\circ}$ and the corresponding $\gamma$ is 0.77 . The results illustrate that the shear stiffness of RPBLs is feasible to be controlled by varying the central angle, and the central angle ratio of one hollow to one sector should be between 0.25 and 0.75 . By using the proper wing size, the yield loads of new RPBLs are close to that of PBL.

4.4. Effects of Offset Angle. Figure 15 shows the new rubber rings with varying offset angles, where the number of sectors and the central angle of hollows are $6^{\circ}$ and $30^{\circ}$, respectively. The considered rotational offsets range from $0^{\circ}$ to $30^{\circ}$ with a step of $7.5^{\circ}$, which covers most of the cases that possibly occur in applications. Besides, the thickness of the rubber rings is $2 \mathrm{~mm}$ in this discussion. Figure 16 shows the shear force-slip curves of the models with different offset angles, where the label C_ns6_o15 denotes a model using the new rubber ring with 6 periodical sectors and a $15^{\circ}$ offset angle. The global shear behavior of these models is close.

From Figures 16(b) and 16(c), the initial shear stiffness of the new RPBLs is slightly affected by the offset angle. As stated above, the contribution of the region near the hole center on the shear stiffness is higher than the region on the side of holes. Compared with the mean shear stiffness, the 


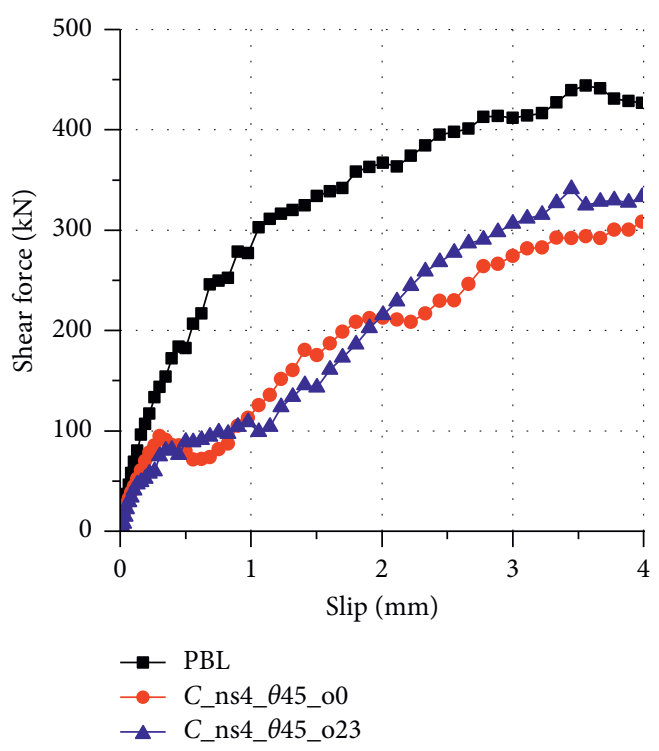

(a)

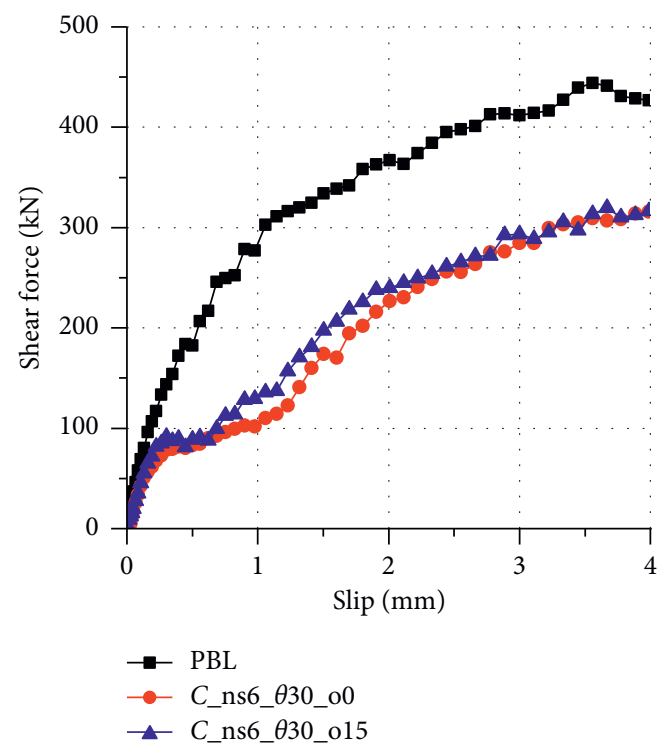

(c)

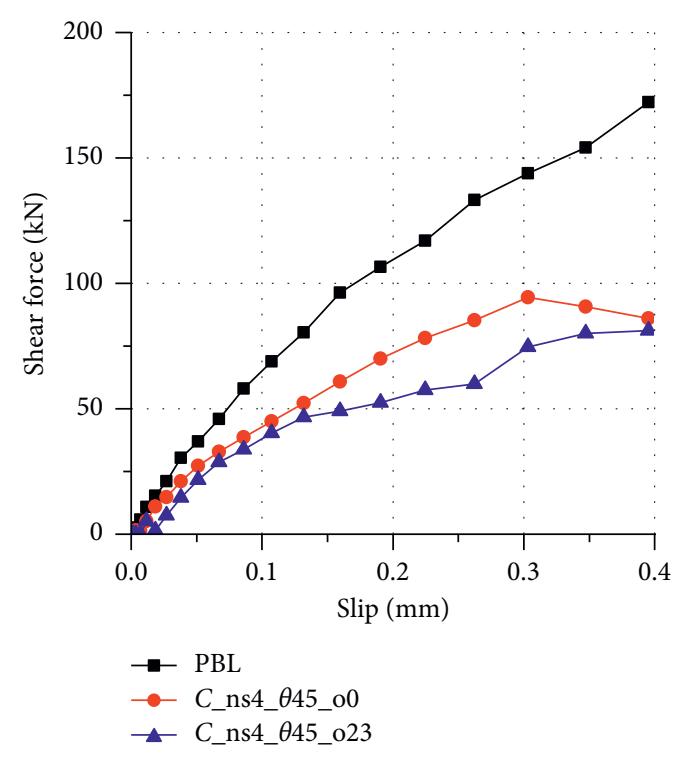

(b)

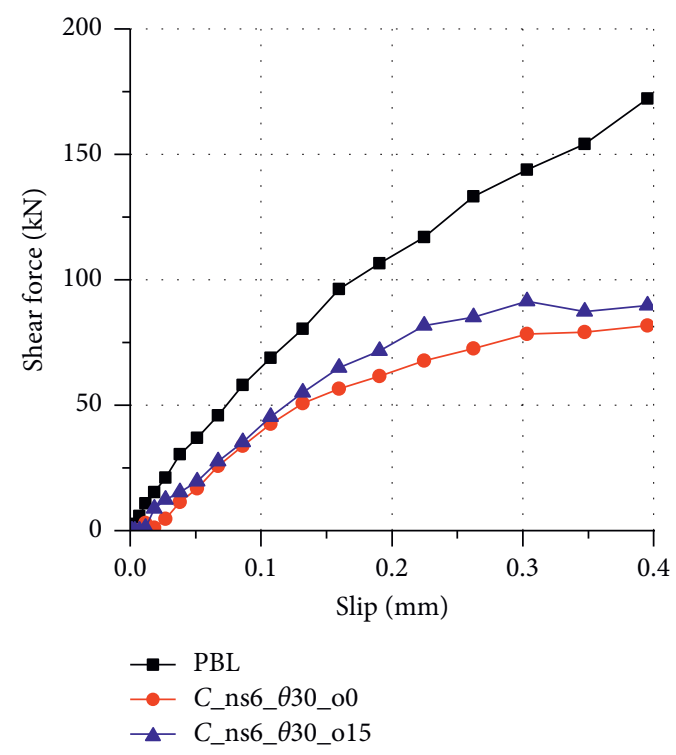

(d)

FIgURE 10: Shear force-slip curves of Type-C rubber rings. (a) Global shear behavior, $n_{s}=4$. (b) Initial loading stage, $n_{s}=4$. (c) Global shear behavior, $n_{s}=6$. (d) Initial loading stage, $n_{s}=6$.

maximum variation is $20 \%$. The yield loads are not impacted by the offset angles. Thus, the shear behavior of new RPBLs is relatively stable when the number of sectors is no less than 6 .

4.5. Effects of Rubber Ring Thickness. Lastly, Figure 17 shows the new rubber rings with a rubber ring thickness of $1.5 \mathrm{~mm}$, $2 \mathrm{~mm}, 3 \mathrm{~mm}$, and $4 \mathrm{~mm}$. The number of sectors, central angles of hollows, and offset angles are $6^{\circ}, 30^{\circ}$, and $0^{\circ}$, respectively. On the concern of the fabrication simplicity of new rubber rings, the smallest thickness of rubber rings considered in this study is $1.5 \mathrm{~mm}$. Besides, the previous analyses [10] concluded that the thickness of rubber rings is unnecessary to be larger than $4 \mathrm{~mm}$ so that the upper limit of the thickness is $4 \mathrm{~mm}$ in this study.
Figure 18(a) shows the shear force-slip curves of the new RPBLs with varying thickness of rubber rings. The thickness of rubber rings considerably influences the yield load of RPBLs and the recovered stiffness at the third loading stage. Both the yield load and the recovered stiffness decrease with the increase of rubber ring thickness. The reason is that the thicker rubber rings reduce the confinement effects on the concrete dowels and also postpone the stiffness recovery that is contributed by uncontacted parts of concrete dowels. Figures 18(b) and 18(c) show that the initial shear stiffness is irrelevant to the thickness of rubber rings when the thickness is no larger than $3 \mathrm{~mm}$, which further demonstrates that the shear stiffness is dominated by the projected contact area between hole walls and concrete dowels. To obtain moderate shear stiffness 


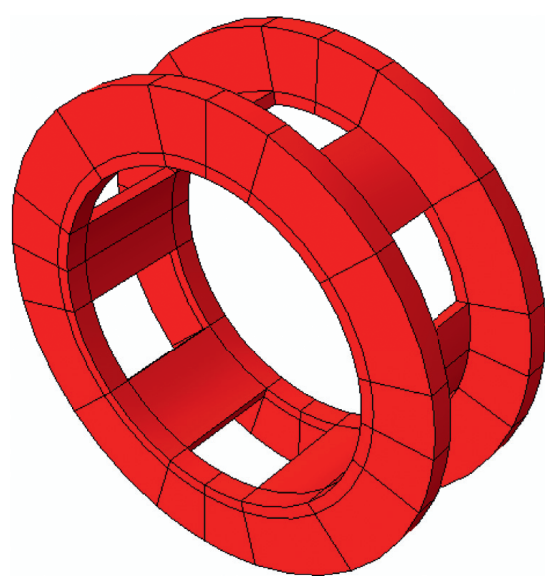

(a)

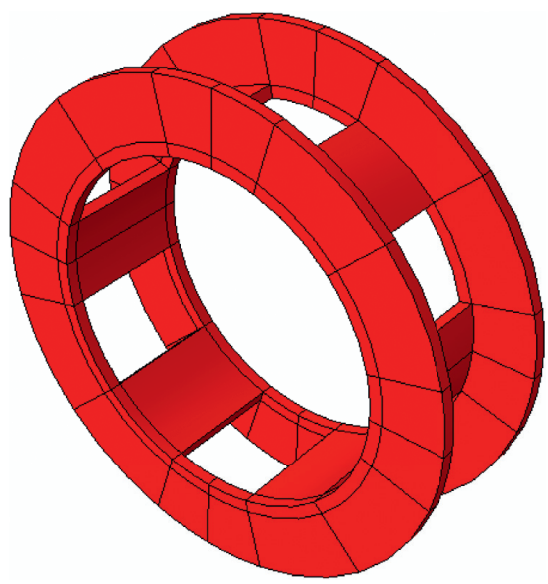

(c)

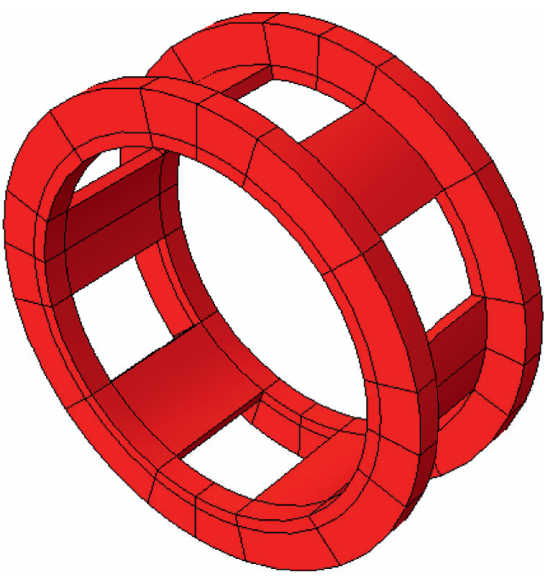

(b)

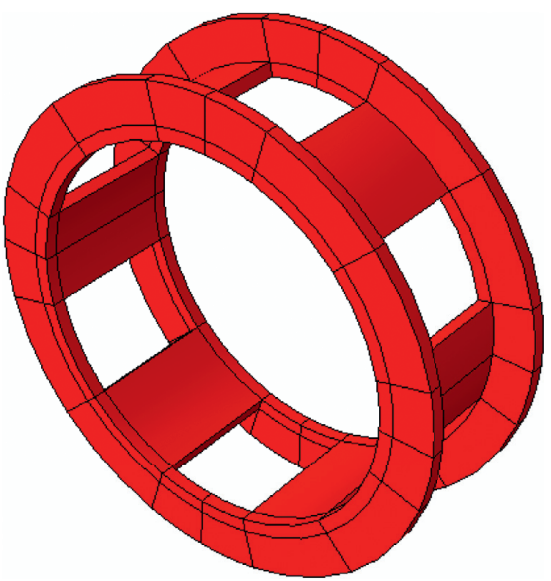

(d)

FIGURE 11: Type-C with varying wing sizes: (a) $t_{w}=4 \mathrm{~mm}, l_{w}=10 \mathrm{~mm}$, (b) $t_{w}=4 \mathrm{~mm}, l_{w}=6 \mathrm{~mm},(\mathrm{c}) t_{w}=2 \mathrm{~mm}, l_{w}=10 \mathrm{~mm},(\mathrm{~d}) t_{w}=2 \mathrm{~mm}$, $l_{w}=6 \mathrm{~mm}$.

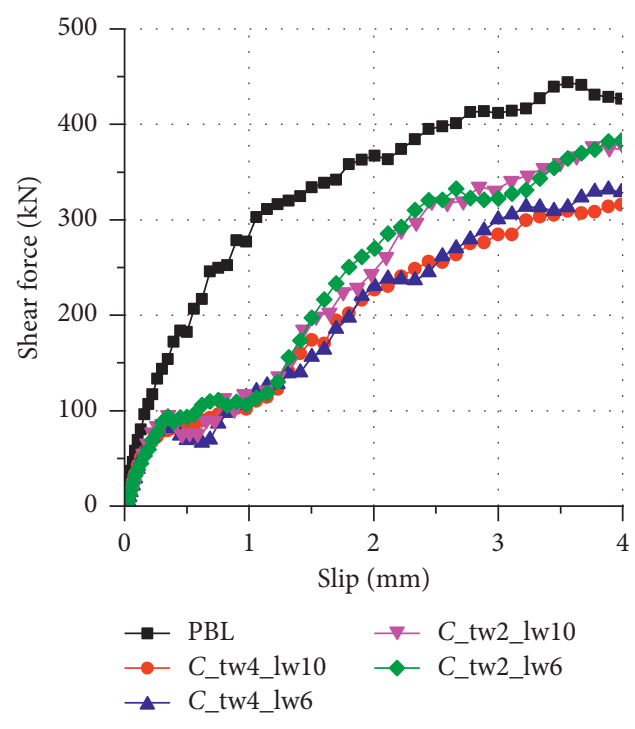

(a)

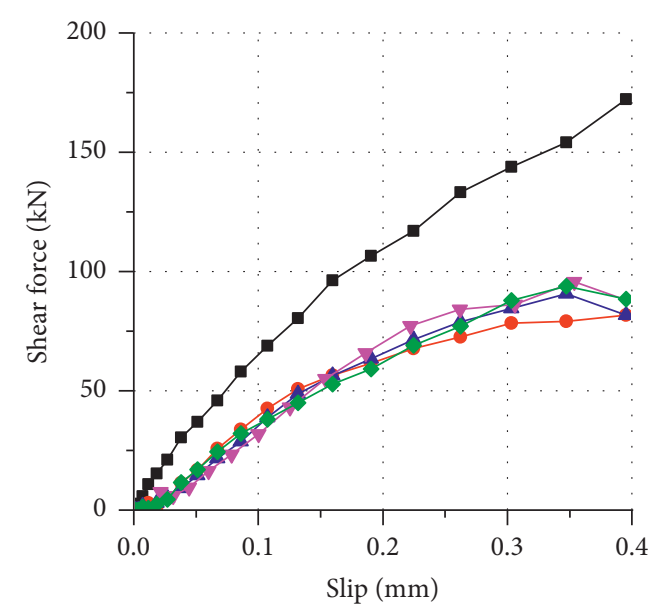

$$
\begin{aligned}
& \rightarrow \text { PBL } \\
& \rightarrow \text { C_tw4_lw10 } \rightarrow \text { C_tw2_lw10 } \\
& \rightarrow \text { C_tw4_lw6 }
\end{aligned}
$$

(b)

Figure 12: Continued. 


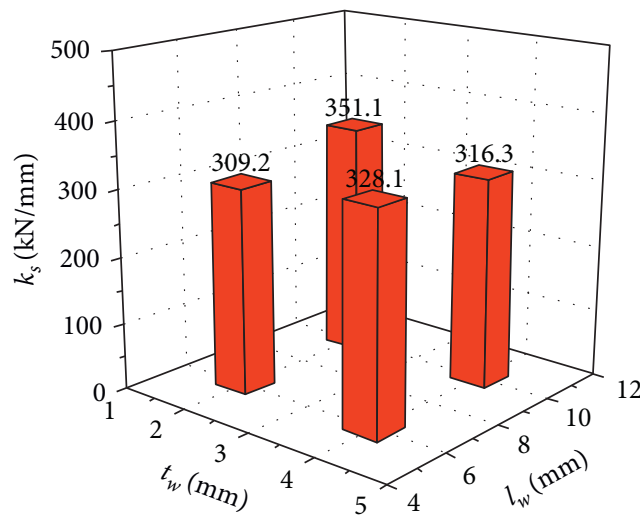

(c)

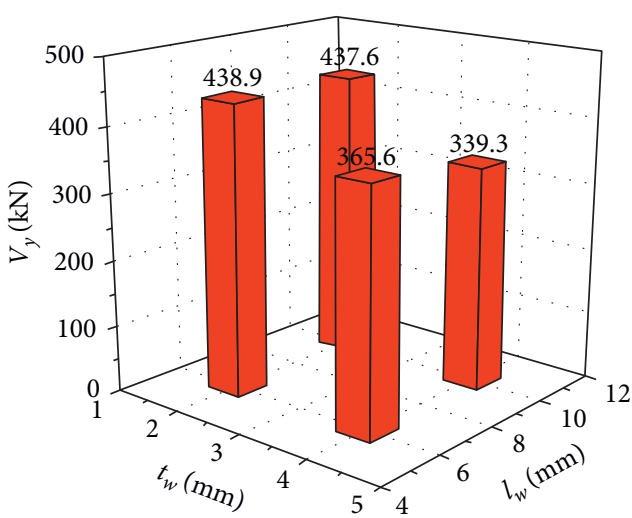

(d)

Figure 12: Effects of side wing sizes. (a) Global shear behavior. (b) Initial shear stiffness. (c) Effects of wing sizes on shear stiffness. (d) Effects of wing sizes on yield loads.

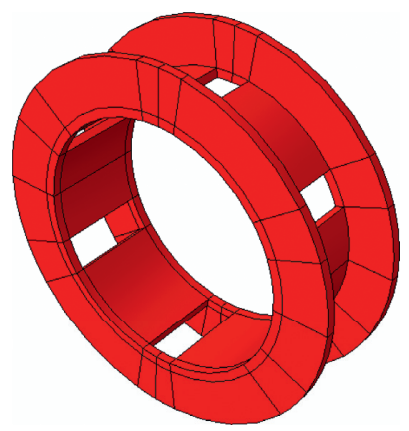

(a)

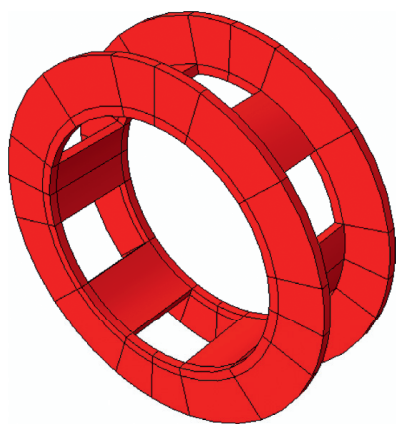

(b)

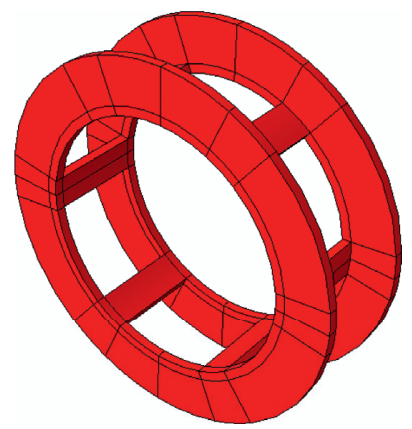

(c)

Figure 13: Type-C with varying central angles: (a) $\theta=15^{\circ}$, (b) $\theta=30^{\circ}$, (c) $\theta=45^{\circ}$.

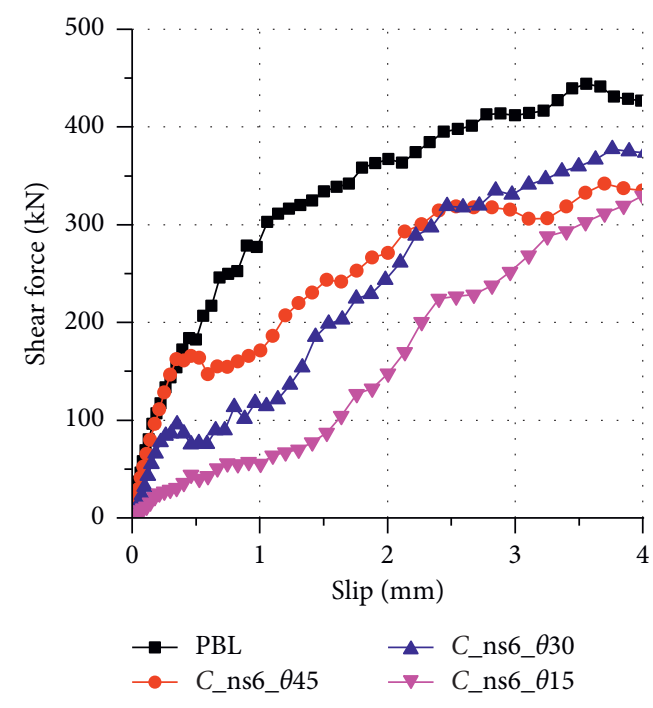

(a)

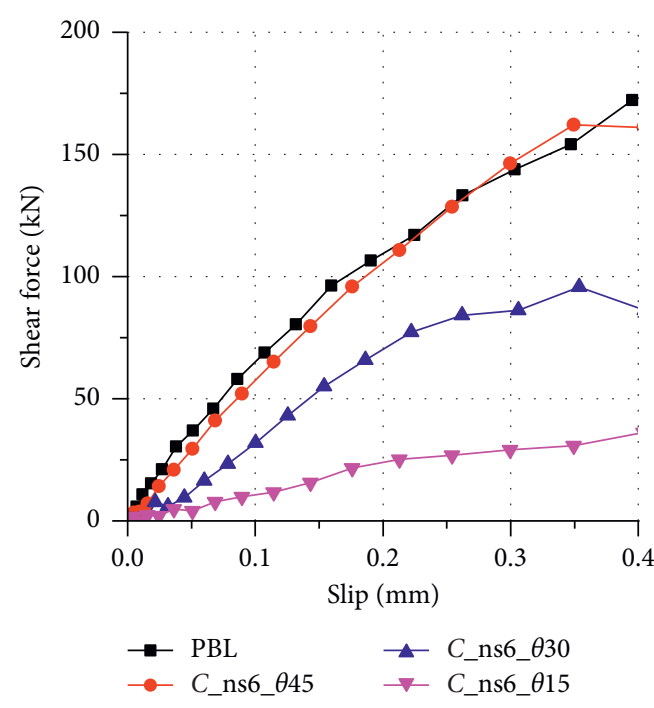

(b)

Figure 14: Continued. 


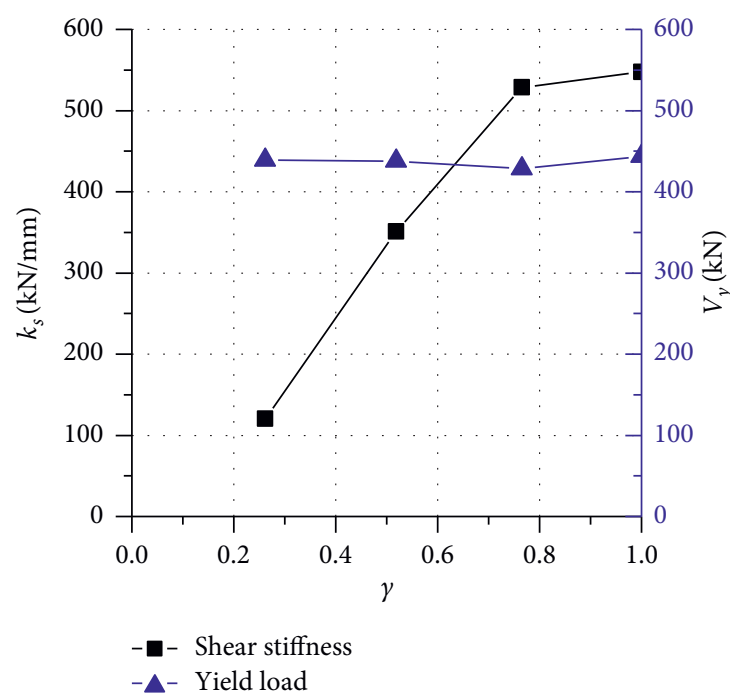

(c)

FIGURE 14: Effects of central angles. (a) Global shear behavior. (b) Initial shear stiffness. (c) Effects of $\gamma$.

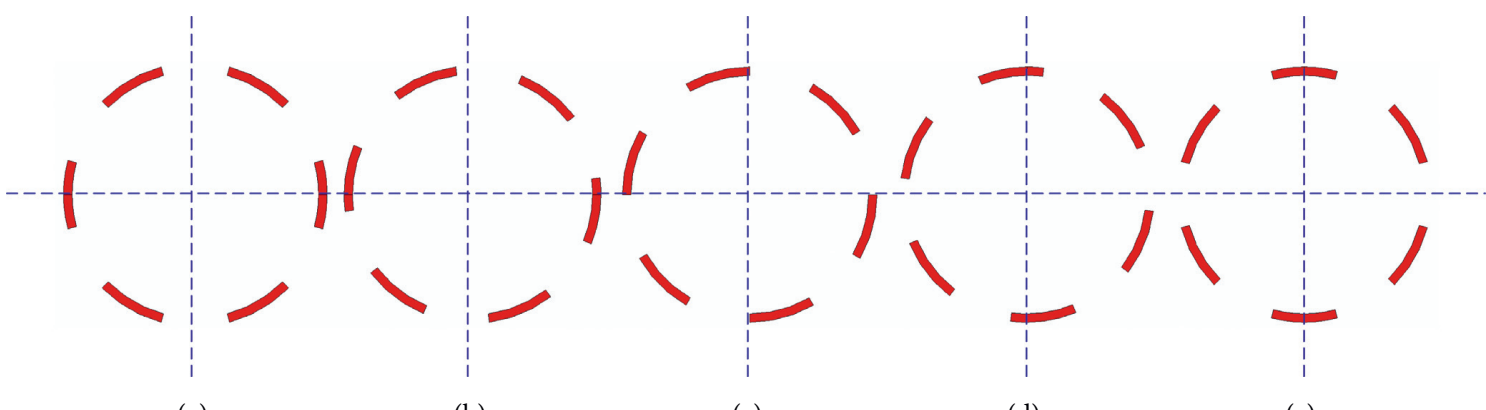

(a)

(b)

(c)

(d)

(e)

Figure 15: Type-C with varying offset angles: (a) $o=0^{\circ}$, (b) $o=7.5^{\circ}$, (c) $o=15^{\circ}$, (d) $o=22.5^{\circ}$, (e) $o=30^{\circ}$.

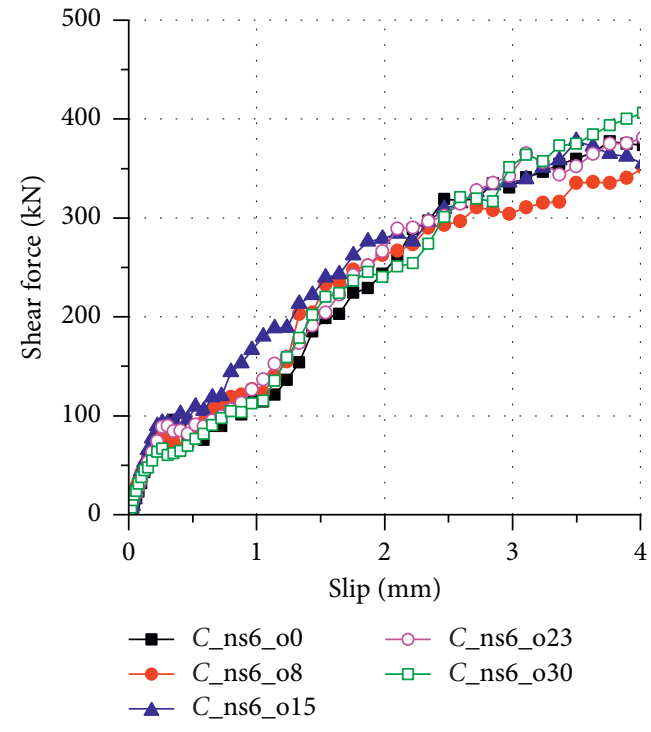

(a)

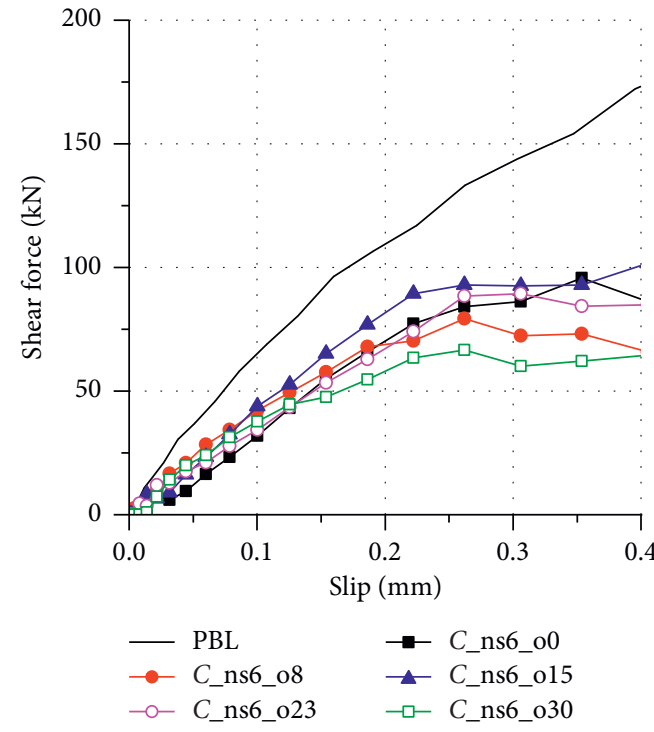

(b)

Figure 16: Continued. 


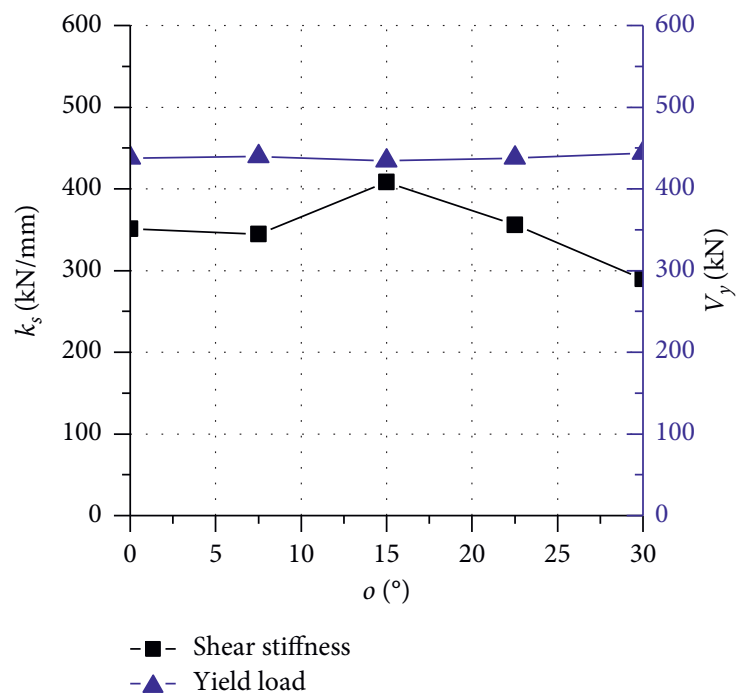

(c)

Figure 16: . Effects of offset angles. (a) Global shear behavior. (b) Initial shear stiffness. (c) Effects of $o$.

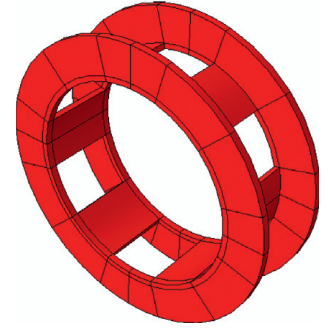

(a)

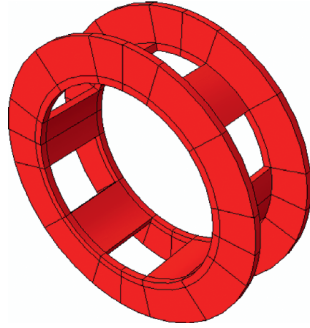

(b)

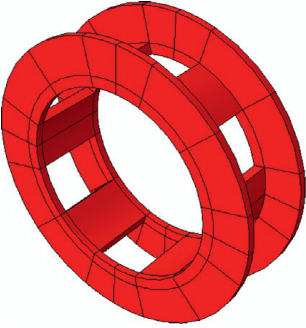

(c)

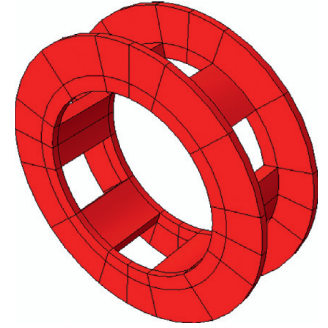

(d)

FIGURE 17: Type-C with varying rubber ring thickness: (a) $t_{r}=1.5 \mathrm{~mm}$, (b) $t_{r}=2 \mathrm{~mm}$, (c) $t_{r}=3 \mathrm{~mm}$, and (d) $t_{r}=4 \mathrm{~mm}$.

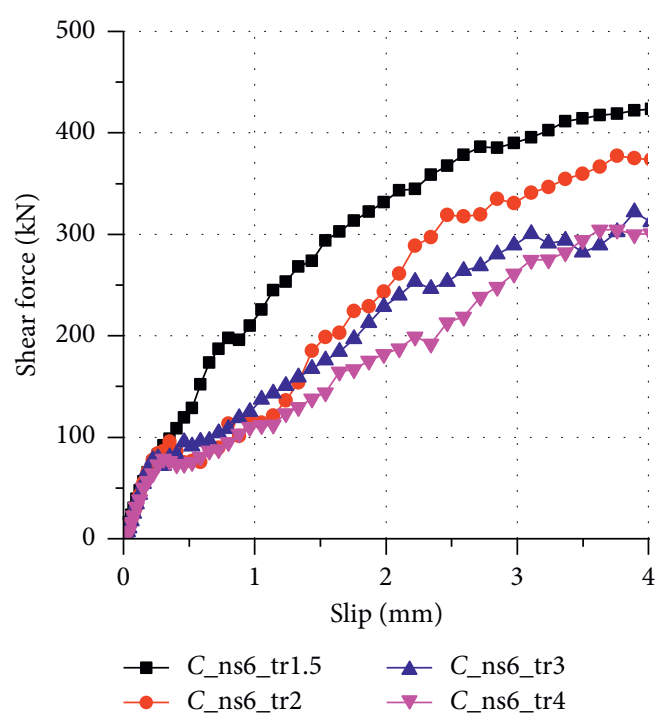

(a)

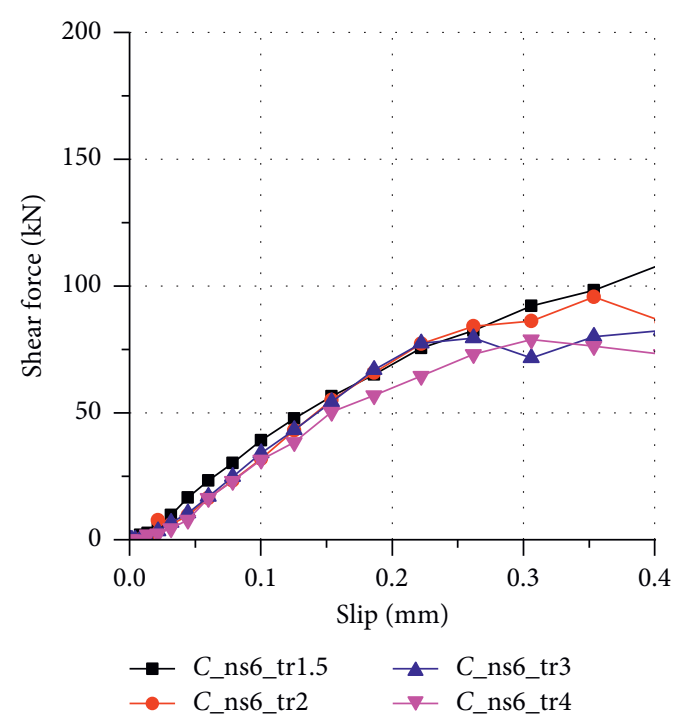

(b)

FIGURE 18: Continued. 


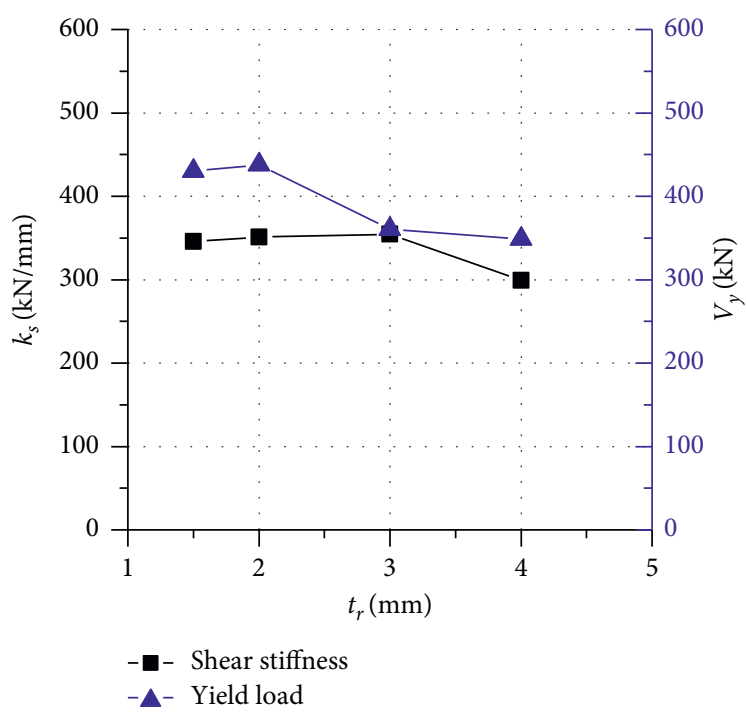

(c)

FiguRE 18: Effects of rubber ring thickness. (a) Global shear behavior. (b) Initial shear stiffness. (c) Effects of $t_{r}$.

and proper yield loads of new RPBLs, the thickness of new rubber rings is suggested as $2 \mathrm{~mm}$.

To sum up, employing the isotropic Type-C rubber ring on a conventional PBL is feasible to make the shear stiffness controllable. The proper thickness and length of side wings are $2 \mathrm{~mm}$ and $10 \mathrm{~mm}$ to improve the yield load and the convenience of installation. According to the required shear stiffness, the central angle ratio of hollows to sectors should be between 0.25 and 0.75 . The effects of offset angles are negligible if the number of periodical sectors is no less than 6. Besides, the thickness of rubber rings is suggested as $2 \mathrm{~mm}$ on the concern of fabrication and obtaining moderate stiffness.

Finally, an analytical equation for the shear stiffness of new RPBLs is proposed by regression analyses based on the numerical results. The shear stiffness of new RPBLs increases with the increase of $\gamma$, the ratio of the horizontal projected length of hollows to the hole diameter. Figure 19 compares the numerical results with the calculated results by equation (1), where the coefficient of determination is 0.89 and the standard variation is 0.12 , which should be improved in future works.

$$
k_{s, \mathrm{RPBL}}=\left(1-(1-\gamma)^{1.37}\right) k_{s, \mathrm{PBL}} .
$$

\section{Conclusion}

This paper proposed a new rubber ring that aims to make the shear stiffness of RPBLs controllable. Firstly, the conceptual design and configuration of the new rubber rings were presented and discussed. Subsequently, FE models for the modified push-out tests of new RPBLs were established based on the validated modeling method [10]. Further, a proposal selection was conducted according to the numerical results. The applicability of the new RPBLs was demonstrated. The effects of the number of sectors, sizes of

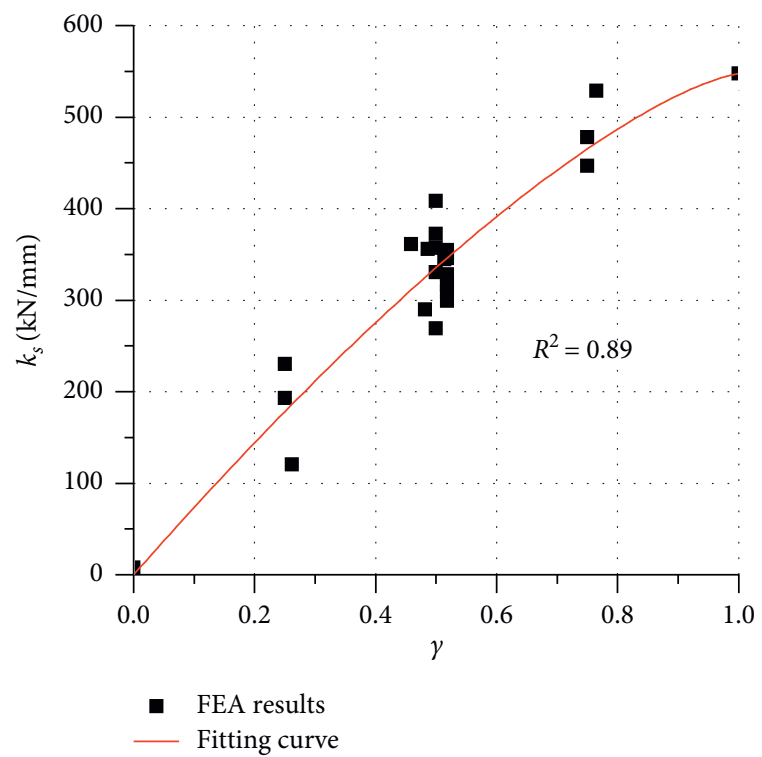

FIgURE 19: Comparison of numerical and calculated results.

side wings, central angles of hollows, offset angles, and thickness of rubber rings were analysed. Finally, the expression for the shear stiffness of new RPBLs was proposed. The following conclusions could be drawn:

(1) The initial shear stiffness is dominated by the horizontal projected contact area between hole walls and concrete dowels. The shear stiffness of new RPBLs is about $35 \%, 60 \%$, and $82 \%$ of the shear stiffness of PBLs when $\gamma$ equals $0.25,0.5$, and 0.75 , respectively. Employing the new rubber rings with varying central angles on conventional PBLs is feasible to obtain the required stiffness for RPBLs.

(2) Based on the numerical results, the proper thickness of side wings is no larger than $2 \mathrm{~mm}$. The thicker side 
wing could reduce the confinement effects provided by surrounding concrete on concrete dowels, resulting in a drop of the yield load of new RPBLs. The central angle ratio of hollows to sectors is the dominant factor in the shear stiffness of RPBLs, which should be in the range from 0.25 to 0.75 .

(3) The number of sectors is suggested to be no less than 6 so that the shear behavior of new RPBLs is irrelevant to the offset angle, which could effectively improve the convenience of installation on site. The shear stiffness is not related to the thickness of rubber rings. To improve the yield load of RPBLs and obtain the moderate recovered stiffness, the thickness of rubber rings is recommended as $2 \mathrm{~mm}$.

\section{Data Availability}

The data used to support the findings of this study are available from the corresponding author upon request.

\section{Conflicts of Interest}

The authors declare that they have no conflicts of interest.

\section{Acknowledgments}

The authors would like to acknowledge Zhejiang Department of Transport for the funding support of Project of Science and Technology Program of Department of Transport, Zhejiang Province (2019049).

\section{References}

[1] Y. Liu, H. Xin, J. He, D. Xue, and B. Ma, "Experimental and analytical study on fatigue behavior of composite truss joints," Journal of Constructional Steel Research, vol. 83, pp. 21-36, 2013.

[2] Y. Liu, S. Wang, H. Xin, and Y. Liu, "Evaluation on out-of-plane shear stiffness and ultimate capacity of perfobond connector," Journal of Constructional Steel Research, Article ID 105850, 2019.

[3] Y. Liu, H. Xin, and Y. Liu, "Load transfer mechanism and fatigue performance evaluation of suspender-girder composite anchorage joints at serviceability stage," Journal of Constructional Steel Research, vol. 145, pp. 82-96, 2018.

[4] J.-H. Ahn, C.-G. Lee, J.-H. Won, and S.-H. Kim, "Shear resistance of the perfobond-rib shear connector depending on concrete strength and rib arrangement," Journal of Constructional Steel Research, vol. 66, no. 10, pp. 1295-1307, 2010.

[5] J. P. S. Cândido-Martins, L. F. Costa-Neves, and P. D. S. Vellasco, "Experimental evaluation of the structural response of perfobond shear connectors," Engineering Structures, vol. 32, no. 8, pp. 1976-1985, 2010.

[6] E. C. Oguejiofor and M. U. Hosain, "A parametric study of perfobond rib shear connectors," Canadian Journal of Civil Engineering, vol. 21, no. 4, pp. 614-625, 1994.

[7] Q.-T. Su, W. Wang, H.-W. Luan, and G.-T. Yang, "Experimental research on bearing mechanism of perfobond rib shear connectors," Journal of Constructional Steel Research, vol. 95, pp. 22-31, 2014.

[8] X. Xu, Y. Liu, and J. He, "Study on mechanical behavior of rubber-sleeved studs for steel and concrete composite structures," Construction and Building Materials, vol. 53, pp. 533-546, 2014.

[9] X. Xu and Y. Liu, "Analytical and numerical study of the shear stiffness of rubber-sleeved stud," Journal of Constructional Steel Research, vol. 123, pp. 68-78, 2016.

[10] Y. Liu, H. Xin, and Y. Liu, "Experimental and analytical study on shear mechanism of rubber-ring perfobond connector," Engineering Structures, vol. 197, Article ID 109382, 2019.

[11] ABAQUS Documentation. Version 6.12. Dassault System. Vélizy-Villacoublay. France, 2012.

[12] CEB-FIP Model Code 2010. British Standard Institution. UK, 2010.

[13] S. Zheng, Y. Liu, T. Yoda, and W. Lin, "Parametric study on shear capacity of circular-hole and long-hole perfobond shear connector," Journal of Constructional Steel Research, vol. 117, pp. 64-80, 2016. 